\section{Further Studies of Porcine Malignant Hyperthermia}

\author{
L. W. HALL, CYNTHIA M. TRIM, N. WOOLF
}

British Medical fournal, 1972, 2, 145-148

\section{Summary}

A non-lethal procedure for identifying pigs apt to develop malignant hyperthermia is described. Susceptible animals were exposed to a variety of anaesthetic and other agents and it was shown that thiopentone sodium and CT 1341 (Glaxo) afforded a measure of protection against the development of the syndrome. Pretreatment with procaine did not prevent the onset of the condition and the administration of procaine when muscle rigidity was present failed to prevent a fatal outcome. The syndrome was induced in susceptible animals by halothane, chloroform, and a combination of halothane with suxamethonium. The effects of cyclopropane in susceptible pigs could not be predicted, and other tests showed that suxamethonium alone would not induce muscle contracture. Pretreatment with lignocaine failed to prevent induction of the syndrome by halothane.

We believe that the porcine syndrome may result from more than one defect and that in one particular type the most effective treatment is immediate cooling coupled with the administration of sodium bicarbonate.

\section{Introduction}

There are many reports of an abnormal response in man and in pigs to halogenated anaesthetic agents either alone or in combination with suxamethonium chloride (Ellis, 1971). This response is characterized by the development of generalized muscle rigidity, a severe and sustained rise in body temperature, hyperkalaemia, and metabolic acidosis.

Since the original report of the syndrome in pigs (Hall, Woolf, Bradley, and Jolly, 1966) an attempt has been made to breed enough experimental animals for further investigation of the syndrome. In order to do this a satisfactory non-lethal testing procedure had to be devised for the recognition of "reactors"- that is, animals in which the syndrome could be produced by the appropriate treatment.

The purpose of this paper is to report this non-lethal testing procedure and to record further experience obtained with the syndrome in 36 litters of specially-bred Landrace cross pigs.

\section{Recognition of "Reactors"}

Various tests, including the injection of small doses of suxamethonium into muscles of one limb and observation of the subsequent behaviour of the animal, were tried but the most successful procedure proved to be intra-arterial injection of suxamethonium in piglets between 6 and 8 weeks of age anaesthetized with halothane.

The animals were anaesthetized with a halothane/oxygen mixture delivered through a facemask. In three or four instances muscular rigidity developed during induction. In these the

\footnotetext{
University Department of Veterinary Clinical Studies, School of Veterinary Medicine, Cambridge

L. W. HALL, M.R.C.V.S., D.V.A., University Lecturer

CYNTHIA M. TRIM, B.V.SC., M.R.C.v.S., Research Assistant

St. George's Hospital Medical School, London S.W.1

N. WOOLF, M.MED.(PATH.), M.R.C.PATH., Reader in Experimental Pathology
}

induction was abandoned and the animal was immediately immersed up to its neck in a bath of cold water. This measure proved to be sufficient to prevent a fatal rise in body temperature, the muscle rigidity passed off after 15 to 25 minutes' immersion, and the animals were then transferred from the bath to the floor. Recovery of consciousness was delayed for one to two hours, and in one animal manipulation of the limbs during this period resulted in a return of muscle rigidity. This animal died after developing hyperpyrexia which could not be controlled by reimmersion in the water-bath. In two animals rigidity was accompanied by respiratory arrest and their jaws had to be prised open, an endotracheal tube passed, and intermittent positivepressure ventilation of the lungs performed during immersion in the bath. Spontaneous breathing returned only after rigidity of the limb muscles had disappeared.

In animals that did not become rigid during induction 2 to 5 mg of suxamethonium chloride (depending on the size of the animal) was injected as a $1 \%$ solution in saline into one femoral artery. In normal pigs this produced fasciculation followed by complete flaccidity in the muscles deriving their blood supply from that artery. The muscular flaccidity was easily recognizable by comparing the ease of flexion of the joints of the hind legs. An intravenous injection of 10 to $25 \mathrm{mg}$ of suxamethonium was then given to confirm the normal response and animals that showed no sign of muscle rigidity after these procedures were classified as "non-reactors."

In animals classified as reactors the fasciculation occurring after the intra-arterial injection was usually violent and was succeeded by rigidity of the involved muscles. Occasionally bulging of the affected muscles was observed, but in every case muscle rigidity was easily recognized by comparison of the ease with which the joints of the hind limbs could be flexed and extended. The rigidity passed off within one to two minutes and the animals were allowed to regain consciousness without being challenged with an intravenous dose of suxamethonium. On one occasion when there was some doubt about the reaction to the intra-arterial injection an intravenous dose of $10 \mathrm{mg}$ was administered, which produced typical generalized muscle rigidity. Immediate immersion in cold water prevented a rise in body temperature, and after a slow recovery from anaesthesia, the animal behaved normally.

\section{Breeding Experiments}

A total of 263 piglets from 36 matings were subjected to the test procedures described and 34 reactors were identified among them. All these piglets were the progeny of a single boar which had shown a positive response during the earliest part of the study and of his dam, litter mate, and offspring. To date, the breeding pattern suggests that the abnormality is being inherited as an autosomal dominant with variable penetrance, occasional litters being found without reactors. In some of these litters, however, piglets died before testing, so this finding must be treated with some reserve. It is also possible that two genes may be involved, and further breeding studies are planned to investigate this.

\section{Effect of Different Anaesthetic Agents}

Muscle stiffness and hyperpyrexia were first recorded in pigs which had received phencyclidine hydrochloride $(0 \cdot 2 \mathrm{mg} / \mathrm{kg})$ and atropine sulphate $(1.8 \mathrm{mg})$ by intravenous injection as premedication before anaesthesia induced with halothane/oxygen. It was believed that the muscle stiffness was caused by the action of suxamethonium given to facilitate endotracheal intubation (Hall et al., 1966). Later, however, it was found that the reaction and death could occur without suxamethonium being given, and the development of the testing procedure showed that the administration of halothane/oxygen could produce 
the syndrome in unpremedicated pigs. Several other anaesthetic agents were subsequently tested in susceptible animals.

\section{THIOPENTONE SODIUM}

Piglets of one litter were anaesthetized with intravenous thiopentone sodium and given the intra-arterial test dose of suxamethonium. No reactors were identified, but seven days later a second test with halothane/oxygen anaesthesia showed the presence of three reactors in the litter of 10 piglets.

An intra-arterial injection of suxamethonium failed to produce contracture in an older, known reactor anaesthetized with thiopentone sodium, but a similar injection given one week later under halothane anaesthesia produced a typical contracture in the ipsilateral limb.

Another known reactor in which a typical generalized response had already been elicited on three previous occasions was anaesthetized with $12.5 \mathrm{mg} / \mathrm{kg}$ of intravenous thiopentone sodium. After intubation with a $9 \cdot 5-\mathrm{mm}$ cuffed endotracheal tube anaesthesia was maintained for 30 minutes with nitrous oxide/oxygen supplemented with increments of thiopentone sodium totalling $425 \mathrm{mg}$. An inspired concentration of $3 \%$ halothane was next administered for three minutes, after which anaesthesia was maintained with a $1.5 \%$ inspired concentration for a further 10 minutes. About 40 minutes after the initial dose of thiopentone sodium $50 \mathrm{mg}$ of suxamethonium chloride was given by intravenous injection, which produced an uneventful period of 12 minutes' respiratory arrest followed by complete recovery. The pig recovered to full consciousness after a further 35 minutes. One week later a typical response was again provoked with halothane/oxygen/suxamethonium.

\section{CT 1341}

Two known reactors were anaesthetized with the steroid mixture CT 1341 (Glaxo) for the placement of an indwelling catheter in the femoral artery. The initial dose approximated to $6 \mathrm{mg} / \mathrm{kg}$ by intravenous injection, and further increments were given as required during the 20-minute operations. On each occasion anaesthesia and recovery were uneventful. One other known reactor was anaesthetized for the same operation by a CT 1341intubation halothane-oxygen sequence. Anaesthesia and recovery were again uneventful.

Two known reactors under CT 1341 anaesthesia were challenged by 15 minutes of halothane inhalation followed by an intravenous dose of suxamethonium chloride. No contracture was produced and subsequent complete recovery was uneventful. When challenged one week later with suxamethonium during halothane/oxygen anaesthesia both animals reacted in a typical manner.

\section{CYCLOPROPANE}

Three known reactors were anaesthetized with cyclopropane/ oxygen and three more with nitrous oxide/oxygen/cyclopropane for periods of 15 to 45 minutes. In all these anaesthesia was uneventful and followed by complete recovery, but another reactor developed a generalized reaction after 50 minutes of cyclopropane anaesthesia.

Two other known reactors were anaesthetized with cyclopropane/oxygen and intubated, and anaesthesia was maintained for 45 minutes with $30 \%$ cyclopropane in oxygen. Partial recovery was allowed and the inspired gases were changed to $3 \%$ halothane in oxygen. In one pig muscular rigidity appeared after three minutes' inhalation of halothane. In the second pig rigidity did not occur when suxamethonium was given after 10 minutes' inhalation of halothane. Seven weeks after these tests the second animal was again anaesthetized with cyclopropane/oxygen for 45 minutes and then allowed to breath 3\% halothane in oxygen. Muscle contracture started 3 minutes after exposure to halothane and body temperature began to rise two minutes later.

\section{CHLOROFORM}

One known reactor developed a typical reaction when anaesthetized with a chloroform/oxygen mixture without the administration of suxamethonium.

\section{METHOXYFLURANE}

One known reactor weighing $45 \mathrm{~kg}$ was anaesthetized for 30 minutes with nitrous oxide/oxygen/methoxyflurane, intubated, and given $50 \mathrm{mg}$ of suxamethonium chloride by intravenous injection. This injection produced eight minutes of apnoea during which the animal was ventilated with $1 \%$ methoxyflurane in a nitrous oxide/oxygen mixture. No muscle stiffness was seen, the body temperature did not rise, and recovery from anaesthesia was complete 13 minutes after the injection.

\section{SUXAMETHONIUM CHLORIDE}

Five known reactors were surgically prepared by the insertion of an indwelling catheter in the femoral artery. Two of these animals removed the catheters and in one the catheter blocked before tests could be carried out. In the remaining two animals injections were made through the catheters four days after their implantation, the animals being conscious and unrestrained. All solutions were warmed to $38^{\circ} \mathrm{C}$ before injection and flushed through the injection catheter with $2 \mathrm{ml}$ of warm normal saline.

Control injections of warm saline produced no observable effect. The first pig, which weighed $20 \mathrm{~kg}$, was given $0.6 \mathrm{ml}$, and the second, a $25-\mathrm{kg}$ animal, $1.0 \mathrm{ml}$ of a $0.5 \%$ solution of suxamethonium chloride. Both animals showed signs of pain or discomfort at the time of visible muscle fasciculation. The affected leg was extended backwards and shaken in the air as the pig walked around the pen. This was followed by obvious weakness of the injected leg which persisted for three to four minutes. No muscle contracture was produced. One week later injection under halothane anaesthesia produced typical contracture in these animals.

Both of these catheterized pigs were subjected to intra-arterial injections of $5 \mu \mathrm{g}$ of adrenaline and $5 \mu \mathrm{g}$ of noradrenaline. No observable effects were produced in the conscious animals by these injections and the catheters were removed by the animals before the injections could be repeated under halothane anaesthesia.

\section{TUBOCURARINE CHLORIDE}

A known reactor weighing $35 \mathrm{~kg}$ was anaesthetized with nitrous oxide, oxygen, and $4 \%$ halothane vapour. As soon as consciousness was lost $10 \mathrm{mg}$ of tubocurarine chloride was given intravenously and an $8-\mathrm{mm}$ cuffed endotracheal tube introduced. Intermittent positive-pressure ventilation of the lungs was performed with a Minivent ventilator using $0.5 \%$ halothane in nitrous oxide/oxygen, and after eight minutes of anaesthesia $50 \mathrm{mg}$ of suxamethonium chloride was injected intravenously. No muscle stiffness developed, the body temperature did not rise, and spontaneous breathing was resumed 72 minutes later after the intravenous administration of $1.2 \mathrm{mg}$ of atropine sulphate and $2.5 \mathrm{mg}$ of neostigmine. Recovery from anaesthesia was uneventful.

This animal was anaesthetized again, when it weighed $59 \mathrm{~kg}$, with a halothane/nitrous oxide/oxygen mixture. After two minutes $15 \mathrm{mg}$ of tubocurarine chloride was injected intravenously and endotracheal intubation performed. Anaesthesia was main- 
tained for 15 minutes with $0.8 \%$ halothane in nitrous oxide/ oxygen using a Minivent ventilator and then $50 \mathrm{mg}$ of suxamethonium chloride was given by intravenous injection. No stiffness or rise in rectal temperature occurred and atropine $(1.2 \mathrm{mg})$ and neostigmine $(2.5 \mathrm{mg})$ were given seven minutes later. Spontaneous breathing returned and the halothane mixture was continued for a further two minutes when it was noticed that the rectal temperature was beginning to rise. The animal was ventilated with nitrous oxide/oxygen because spontaneous respiration became inadequate and fatal cardiac arrest occurred 40 minutes after the neostigmine injection, when the rectal temperature had risen by $2^{\circ} \mathrm{C}$. Full rigor mortis developed within 15 minutes of cardiac arrest.

A second pig from the same litter weighing $60 \mathrm{~kg}$ was anaesthetized in a similar manner and ventilated for 30 minutes with halothane/nitrous oxide/oxygen after the injection of $15 \mathrm{mg}$ of tubocurarine. No reaction occurred during this time but rigidity developed immediately after an injection of $50 \mathrm{mg}$ of suxamethonium given at the end of this period. The rectal temperature rose $3.5^{\circ} \mathrm{C}$ over the next 54 minutes and the pig was then killed by the intravenous injection of pentobarbitone sodium (Euthatal).

\section{LIGNOCAINE HYDROCHLORIDE}

A known reactor weighing $30 \mathrm{~kg}$ was given $40 \mathrm{ml}$ of $2^{\circ}$, lignocaine hydrochloride $(0.8 \mathrm{~g})$ by intramuscular injection. Twenty minutes later opisthotonos developed and there were convulsive movements of the hind legs. At this stage anaesthesia was induced with a halothane/oxygen mixture. Contracture of the hind limb muscles became apparent after seven minutes of halothane anaesthesia and the animal's rectal temperature was found to be $38.0^{\circ} \mathrm{C}$. Halothane was immediately discontinued and pure oxygen administered through the facemask.

About 20 minutes after the induction of anaesthesia there was no sign of returning consciousness, the rectal temperature was $38.8^{\circ} \mathrm{C}$, and respiratory arrest occurred. The animal was intubated and ventilated with oxygen. Fifteen minutes later the rectal temperature was $40.5^{\circ} \mathrm{C}$ and $15 \mathrm{ml}$ of $1^{\circ} \%$ lignocaine hydrochloride was injected into the epidural space at the lumbosacral junction. The rectal temperature rose steadily, and 52 minutes after induction of anaesthesia it was $42 \cdot 0^{\circ} \mathrm{C}$. At this stage $250 \mathrm{mg}$ of thiopentone sodium was given intravenously. The temperature continued to rise and seven minutes later when it was $42.5^{\circ} \mathrm{C}$ an intravenous injection of $15 \mathrm{mg}$ of tubocurarine chloride was given. This, too, failed to prevent any further rise in temperature and the animal was killed with intravenous pentobarbitone sodium 67 minutes after the induction of anaesthesia, when its rectal temperature was $42 \cdot 8^{\circ} \mathrm{C}$.

\section{PROCAINE HYDROCHLORIDE}

One known reactor weighing $43 \mathrm{~kg}$ was given $1.5 \mathrm{~g}$ of procaine hydrochloride by intramuscular injection. Forty minutes later anaesthesia was induced with $4 \%$ halothane in oxygen. Obvious muscle rigidity appeared after 10 minutes' inhalation of halothane and the animal's rectal temperature began to rise after a further three-and-a-half minutes.

Another known reactor weighing $18 \mathrm{~kg}$ was anaesthetized with halothane/oxygen and intubated with a $7.5 \mathrm{~mm}$ bore tube, and muscle contracture was induced after 15 minutes of anaesthesia by the intravenous injection of $20 \mathrm{mg}$ of suxamethonium chloride. The animal was then ventilated with oxygen by means of a Minivent ventilator. Isoprenaline $(1 \mu \mathrm{g} / \mathrm{ml})$ in normal saline was slowly infused into a vein in the right ear while procaine hydrochloride $\left(0 \cdot 6^{\circ} \%\right)$ was infused fairly rapidly into a vein in the left ear. Over a 25 -minute period $0.6 \mathrm{~g}$ of procaine hydrochloride was administered with sufficient isoprenaline to maintain cardiovascular function (as judged by palpation of the femoral pulse and the pattern of the electrocardiogram) within normal limits. During this period the animal's rectal temperature rose steadily to $41 \cdot 7^{\circ} \mathrm{C}$ and death occurred 10 minutes later.

A third known reactor weighing $43 \mathrm{~kg}$ was given $50 \mathrm{ml}$ of $2 \%$ procaine hydrochloride with $1: 100,000$ adrenaline and $7 \mathrm{ml}$ of $5 \%$ procaine hydrochloride, also with adrenaline, by slow intravenous injection over a period of 18 minutes. This injection of about $30 \mathrm{mg} / \mathrm{kg}$ of procaine produced muscle tremors and twitching of muscle masses. Anaesthesia was then induced with halothane/nitrous oxide/oxygen mixture and after seven minutes of anaesthesia the animal's hind legs became stiff. The rectal temperature rose to $39^{\circ} \mathrm{C}$ and general muscle rigidity developed over the next three minutes. Anaesthesia was terminated and the active measures described below prevented a fatal outcome. Twenty minutes later the pig was attempting to sit up and subsequent recovery was uneventful.

\section{Treatment}

Body surface cooling in a bath of cold tap-water prevented a fatal outcome in 14 out of 25 pigs which showed generalized muscle stiffness. When cooling was begun after a rise of more than $1{ }^{\circ} \mathrm{C}$ in rectal temperature there were no survivors. Three of the animals that died had a fatal relapse after an initial improvement shown by muscle relaxation and decrease in rectal temperature.

Six pigs in which muscle stiffness was firmly established were successfully treated by infusion of $5 \%$ sodium bicarbonate and water-bath cooling. Three of these were ventilated with oxygen by means of a Minivent ventilator when spontaneous breathing stopped. In one animal the rectal temperature had risen by $0.5^{\circ} \mathrm{C}$ and in another two animals by $1^{\circ} \mathrm{C}$ before treatment was instituted. The rectal temperature was not recorded in the other three animals. Sodium bicarbonate was infused slowly until muscle movement was seen - that is, return of spontaneous breathing in those being ventilated and limb movements in the others. There was no dose/weight correlation but the amount of bicarbonate necessary appeared to be related to the time between onset of stiffness and start of treatment. An 11-kg pig was ventilated and cooled for 56 minutes before being given $40 \mathrm{ml}$ of $5 \%$ sodium bicarbonate. Before this injection spontaneous respiratory movements were weak and shallow, but four minutes later respiration was adequate and extubation was followed by complete recovery. A $40-\mathrm{kg}$ pig completely stiff after halothane inhalation and showing a rise of $0.5^{\circ} \mathrm{C}$ in rectal temperature treated by the immediate infusion of bicarbonate coupled with body surface cooling required only $10 \mathrm{ml}$ of the bicarbonate solution to produce limb movements, which were followed by rapid and complete recovery within five minutes.

\section{Discussion}

It seems probable that the malignant hyperthermia syndrome occurring in this strain of Landrace cross pigs differs from that seen in other breeds of pig. In Poland-China and Pietrain pigs dyspnoea, hyperthermia, and immediate rigor mortis can be induced by environmental stress such as exercise, transportation, and high ambient temperature (Nelson, quoted by Ellis, 1971). To the best of our knowledge our pigs develop the syndrome only when anaesthetized, and exercise, transportation, and high ambient temperatures have never produced anything resembling the condition. However, because there were nine deaths in the 36 litters before testing it is impossible to be certain that death did not occur in animals where the trait was so very strongly expressed that environmental factors could and did produce the condition.

The syndrome seen in these pigs appears to be more akin to that reported by Harrison et al. (1969), although there are some striking differences. For example, those workers were able to use thiopentone/nitrous oxide anaesthesia to set up their experimental preparations before the induction of stiffness. In our 
pigs, however, thiopentone appeared to give protection against the initiation of the syndrome by either halothane alone or the halothane/suxamethonium combination. In South African pigs halothane can initiate the syndrome in the presence of neuromuscular block produced by tubocurarine (Harrison, 1971), and we were able to produce the syndrome in our known reactors given this relaxant, although in these animals the course of the reaction was modified. We agree (Hall et al., 1966), however, that non-depolarizing relaxants have no therapeutic effect once the syndrome is established. Our results also confirm the findings of Harrison et al. (1969) that adrenaline will not produce muscle contracture in susceptible animals, supporting the contention that in our pigs, and possibly in the South African pigs, environmental stress fails to produce the syndrome.

It is also interesting to note that while the American workers quoted by Ellis (1971) claimed that magnesium ions protect their pigs from developing malignant hyperthermia Harrison et al. (1969) found that magnesium sulphate completely lacked therapeutic effect.

In 1970 Kalow suggested that malignant hyperthermia in man could be a syndrome resulting from more than one defect, and the conflicting findings in pigs suggest that the same may be true for the porcine syndrome. Thus although we believe that the pig is proving to be a valuable experimental animal for the study of this condition great caution must be exercised in transposing results from one breed or strain of pigs to another breed or strain, or to man.

Our investigations are far from complete but this early report is prompted by the lack of any specific treatment for the syndrome based on a knowledge of its pathogenesis. We believe that at present immediate cooling coupled with sodium bicarbonate administration provides the best chance of success when dealing with the type of syndrome seen in our pigs. We were unable to show any indication for the administration of procaine hydrochloride, which was reported by Harrison (1971) to be a promising line of treatment for his animals.

This work was supported by a grant from the Medical Research Council, and one of us (C.M.T.) was in receipt of a grant from the Horserace Betting Levy Board. We are grateful to Mr. R. G. Walker for his help in carrying out the intra-arterial injections.

\section{References}

Ellis, F. R. (1971). Anaesthesia, 26, 540

Hall, L. W., Woolf, N., Bradley, J. W. P., and Jolly, D. W. (1966). British Medical fournal, 2, 1305 .

Harrison, G. G. (1971). British Medical fournal, 3, 454

Harrison, G. G. et al. (1969). British fournal of Anaesthesia, 41, 844

Kalow, W. (1970). Proceedings of the Royal Society of Medicine, 63, 178.

\section{MEDICAL MEMORANDA}

\section{Hypertension and Oedema Complicating Pregnancy in Addison's Disease}

\section{E. A. M. NORMINGTON, D. DAVIES}

British Medical fournal, 1972, 1, 148-149

Pregnancy associated with Addison's disease is rarely complicated by pre-eclamptic toxaemia. Toxaemia has been reported in Addison's disease (Cohen, 1948; Langford, 1965), after bilateral adrenalectomy (Moses et al., 1959; Barber et al., 1966), while in the case reported by Strickland and Sode (1967) the patient had recurrent oedema only.

\section{Case Report}

The patient had had uncomplicated full-term pregnancies in 1953 and 1958. In 1960 she had a severe episode of "gastroenteritis" with admission to an infectious diseases hospital and requiring intravenous fluid and steroid therapy for hypovolaemic shock. In May 1961 she presented at Manchester Royal Infirmary with weakness, loss of weight, exertional breathlessness, loss of libido, and scanty but regular menstruation. She was found to have increased generalized pigmentation, especially in palmar creases and buccal mucosa, with diminished body hair. Blood pressure was $90 / 65 \mathrm{~mm} \mathrm{Hg}$. Urinary 17 -oxosteroid excretion was $1-2 \mathrm{mg} / 24$

St. Mary's Hospitals, Manchester

E. A. M. NORMINGTON, M.B., CH.B., M.R.c.o.G., Tutor in Obstetrics

Manchester Royal Infirmary, Manchester

D. DAVIES, M.B., B.CHIR., M.R.C.P., Lecturer in Clinical Endocrinology $\mathrm{hr}$, and 17-oxogenic steroids never exceeded $1 \mathrm{mg} / 24 \mathrm{hr}$ and did not rise after corticotrophin gel 60 units daily for three days. Only $40 \%$ of a water load was excreted in four hours. Abdominal $x$-ray examination did not show adrenal calcification.

She remained well on replacement therapy and in early 1969 was receiving $12.5 \mathrm{mg}$ of cortisone acetate twice daily and 9 $\alpha$-fluorohydrocortisone acetate $0.1 \mathrm{mg}$ daily. Routine serum electrolyte measurements were normal and lying and standing blood pressure was regularly $110 / 80 \mathrm{~mm} \mathrm{Hg}$.

She was first seen in her third pregnancy at 16 weeks' gestation on 29 May 1969, when the uterus corresponded to dates. (Last menstrual period 7 February, expected date of confinement 14 November.) She was seen again at 19 weeks' gestation and the uterine size was that of a 24-week pregnancy. From that time the uterine size did not accord with dates. Fetal movements had been felt for two weeks. Blood pressure was $110 / 80 \mathrm{~mm} \mathrm{Hg}$ and her weight was $49 \mathrm{~kg}$. At 22 weeks the size of the uterus corresponded to a gestation of 34 weeks, with pronounced hydramnios and with an increase in weight to $54 \mathrm{~kg}$. Blood pressure had risen to $125 / 75 \mathrm{~mm} \mathrm{Hg}$, but urine analysis was normal. Abdominal $x$-ray examination confirmed a normal twin pregnancy with radiological maturity corresponding with dates.

Five days later, after admission, her weight had risen to $57.8 \mathrm{~kg}$ and the blood pressure to $140 / 100 \mathrm{~mm} \mathrm{Hg}$. Severe oedema had developed but urine analysis remained normal. Frusemide $40 \mathrm{mg}$ was added to her treatment without improvement. Three days later the fludrocortisone was discontinued and within 24 hours the blood pressure had fallen to $120 / 85 \mathrm{~mm} \mathrm{Hg}$. This level was maintained for six days, when fludrocortisone was reinstituted. Serum electrolytes remained normal (see Chart). Within 24 hours ine blood pressure rose and four days later had reached 140/100 $\mathrm{mm} \mathrm{Hg}$. Once more the fludrocortisone was discontinued with resultant fall in blood pressure to $120 / 80 \mathrm{~mm} \mathrm{Hg}$. Abdomina girth had reached $102.5 \mathrm{~cm}$ and weight was constant at $57.6 \mathrm{~kg}$.

The clinical state remained virtually unchanged for 11 days, but at that time the serum sodium level fell to $131 \mathrm{mEq} / 1$. and postural hypotension occurred for the first time. Fludrocortisone was started again but the blood pressure remained constant at $110 / 70 \mathrm{~mm} \mathrm{Hg}$ though the serum electrolytes returned to normal and the postural hypotension disappeared. The Kober chromogen level fell from the average level of $5 \mathrm{mg} / 24 \mathrm{hr}$ to $1.5 \mathrm{mg} / 24 \mathrm{hr}$ 